ISSN: 2638-5228

Volume 2, Issue 2, 2019, PP: 1-4

\title{
Intravesical Ureterocele into Childhoods: Report of Two Cases and Review of Literature
}

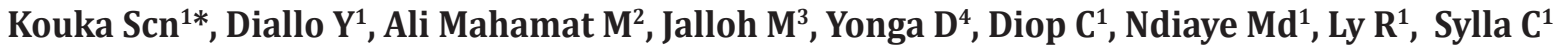 \\ ${ }^{1}$ Departement of Urology, Faculty of Health Sciences, University of Thies, Senegal. \\ ${ }^{2}$ Departement of Urology, University of N'Djamena, Tchad. \\ ${ }^{3}$ Departement of Urology, University Cheikh Anta Diop of Dakar, Senegal. \\ ${ }^{4}$ Service of surgery, County Hospital in Mbour, Senegal. \\ saintkouka@yahoo.fr
}

*Corresponding Author: Kouka SCN, Department of Urology, Faculty of Health Sciences, University of Thies, Senegal.

\begin{abstract}
Congenital ureterocele may be either ectopic or intravesical. It is a cystic dilatation of the terminal segment of the ureter that can cause urinary tract obstruction in children. The authors report two cases of intravesical ureterocele into two children: a 7 years-old girl and 8 years-old boy. Children were referred for abdominal pain. Ultrasound of the urinary tract and CT-scan showed intravesical ureterocele, hydronephrosis and dilatation of ureter. The girl presented a ureterocele affecting the upper pole in a duplex kidney and in the boy it occurred in a simplex kidney. They underwent a surgical treatment consisting of an ureterocelectomy with ureteral reimplantation according to Cohen procedure. The epidemiology, classification, diagnosis and management aspects are discussed through a review of literature.
\end{abstract}

Keywords: intravesical ureterocele, urinary tract obstruction, surgery.

\section{INTRODUCTION}

Ureterocele is an abnormal dilatation of the terminal segment of the intravesical ureter [1]. It is a rare congenital anomaly. Its incidence varies from $1 / 500$ [2] to $1 / 4000$ newborns [2,3]. In Senegal, few cases have been described [4]. The treatment is mostly conservative endoscopic. Open surgery has been proposed in Senegal.

\section{CASE REPORT}

\section{Case 1}

A 7-year-old girl was referred to the pediatric department for abdominal pain with an ultrasound examination indicating the diagnosis of a cystic mass in the form of a round image occupying a portion of the bladder, accompanied by a left hydronephrosis. She had not symptoms of dysuria, no fever and no hematuria. Physical examination was also unremarkable. Creatinine and routine urine examination were normal. CT scan of the abdomen showed a cystic dilatation of left distal ureter associated with left hydronephrosis in a duplex kidney. The contralateral kidney was normal (fig.1.A). Intravenous Urography revealed two left ureters with a complete duplication (fig.1.B). For open surgery we used a modified pararectal incision ("false Pfannenstiel"). The excision of the distal part of the ureterocele was complete. Dissection of a small intra-vesical ureterocele can be performed by pure intravesical route. The reimplantation is carried out transversely according to the technique of Cohen. The point of entry into the bladder is at the upper level of the muscular hiatus followed by a reconstruction of its lower part.

\section{Case 2}

An 8-year-old boy was referred to the pediatric department for abdominal pain with an ultrasound examination indicating a cystic mass described as a round image occupying a portion of the bladder with left hydronephrosis. He had no voiding dysfunction, no fever or hematuria complains. His physical examination was also unremarkable. His creatinine 
Intravesical Ureterocele into Childhoods: Report of Two Cases and Review of Literature

and routine urine examination were normal. CT scan of the abdomen showed a single renal system with an intravesical ureterocele displaying the shape of a "cobra head" associated with left hydronephrosis (fig.2A). The contralateral kidney was normal. For open surgery we used modified para rectal incision ("false Pfannenstiel"). The excision of the distal part of the ureterocele was complete. Dissection of a small intra-vesical ureterocele can be performed by pure intravesical route. The reimplantation is carried out transversely according to the technique of Cohen. The point of entry into the bladder is at the upper level of the muscular hiatus followed by a reconstruction of its lower part.
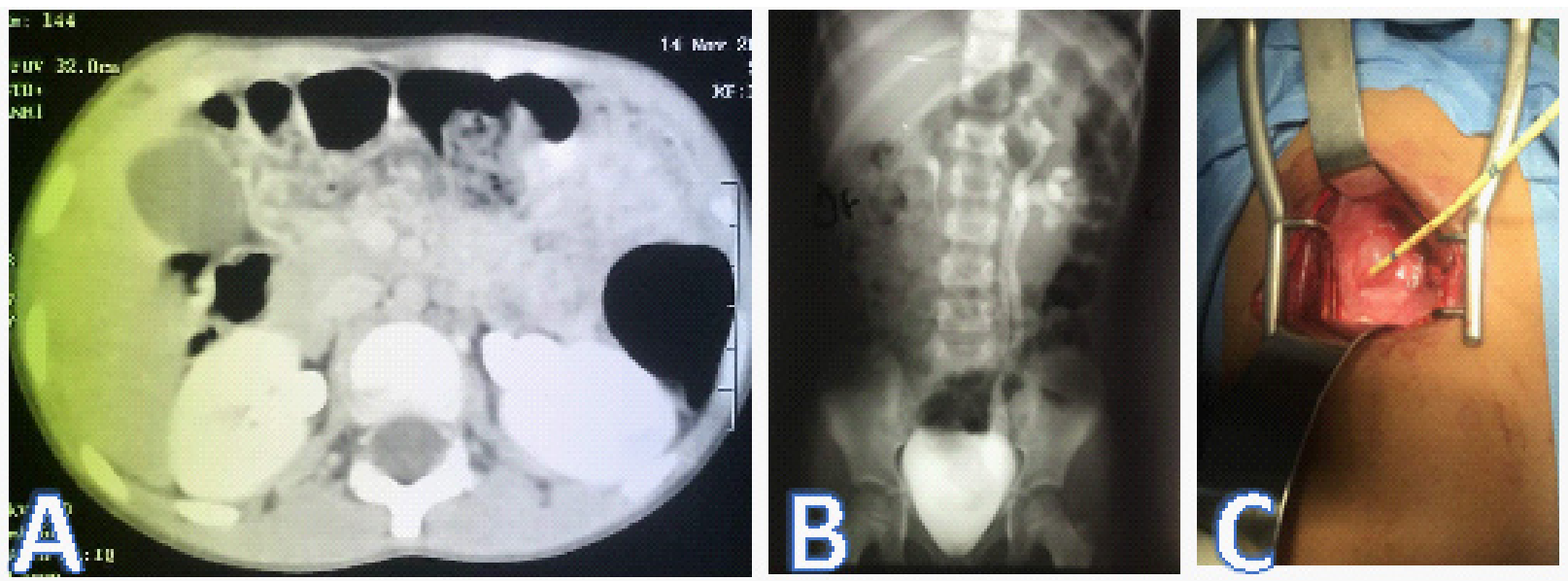

Fig 1. Intravenous pyelography demonstrating two left ureters with a complete duplication (fig.1.B) with dilatation of the upper pole drains into the ureterocele. The contralateral kidney was normal (fig.1.A). Open surgery demonstrating a collapsed ureterocele sitting on the bladder (fig.1C).
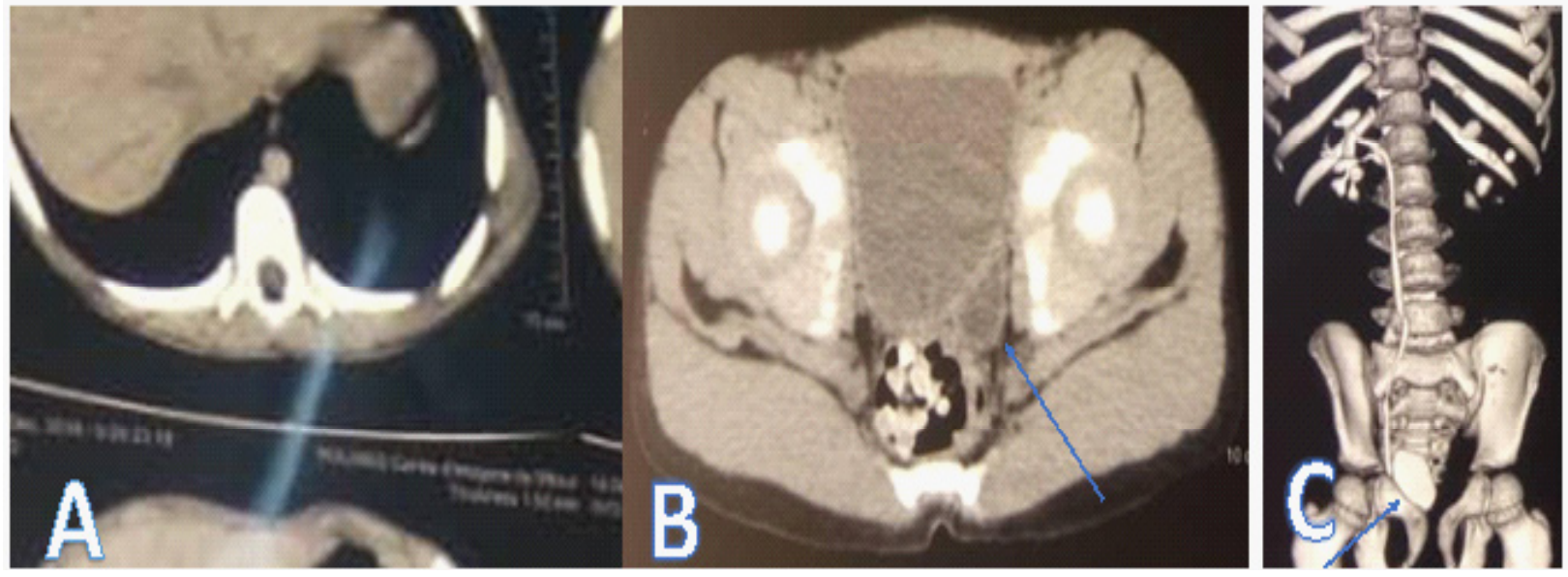

Fig 2. CT scan demonstrating a single system on the left side with left hydronephrosis and a single renal system (fig. 2A). CT reconstruction with an intravesical ureterocele displaying the shape of a "cobra head" associated (fig.2C).

\section{Discussion}

The term ureterocele was created by Leshnew in 1912 and defines a pseudo-cystic dilation of the submucosal segment of the intravesical ureter, between the detrusor hiatus and the ureteral meatus [1-14]. It has extremely variable aspects according to its size, its development towards the cervico-urethral sector, the single or double character of the excretory urinary tract upstream. In children, this urinary malformation is 4 to 6 times more frequent in girls than in boys [5-7]. In our series, we found perfect equality with a sex ratio of $1 / 1$. There are as many ureteroceles on the right as on the left and a bilateral one in $10 \%$ of cases [6].

Several classifications of ureteroceles have been reported, based on anatomopathological criteria. 
Ericsson adopted the first classification of ureterocele in 1954 [7]. He divided them into "simple" and "ectopic". The ureterocele can be classified according to the excretory urinary tract it drains. It can be single or double. The Committee on Terminology of the Urologic Section of the American Academy of Paediatrics [5] proposed the following classification:

- Ureteroceles located outside of the bladder is named ectopic

- Ureteroceles contained entirely within the bladder are orthotopic or intravesical, while an ureterocele that has a portion permanently

Non-obstructing ureterocele is rare. Most frequently ureterocele is obstructing and cause a dilatation of the upper urinary system. Stenotic ureteroceles are completely located inside the blader and they have a small orifice. Stephens [8] classified the intravesical ureterocele associated with ureteral duplication according to the presence of intrinsic obstruction of the ureteral orifice causing it to be non obstructed or stenotic. The non-obstructed ureterocele is visible when peristaltis waves remain.

The classification of Bruezière and Bondonny [6] remains the most used because it is simple, adapted to the clinical context and the therapeutic proposals. It has 4 types:

- Type A: intra-vesical ureterocele on simple ureter.

- $\quad$ Type B: ectopic ureterocele on simple ureter.

- $\quad$ Type C: intra-vesical ureterocele on pyelo-ureteral duplicity.

- Type D: ectopic ureterocele on pyelo-uretral duplicity.

According to Coplen [9], the ureterocele of the child occurs on the superior collecting system in 80 to $95 \%$ of cases. Brueziere [6] found that ureterocele on ureter simplex represents $25 \%$ of all ureteroceles and occurs slightly more often in boys than in girls.

After birth, the clinical presentation is urinary infection, lumbar pain (low back pain, renal colic), voiding dysfunction (pollakiuria, dysuria), acute urinary retention and hematuria. In our case of ureteral duplication, the ipsilateral inferior collecting system was the site of reflux, since the expansion of the ureterocele within the bladder wall interferes with anti-reflux mechanisms $[2,6]$. Physical examination of our patients was strictly normal.

Ultrasound of the urinary tract was performed in our two patients. It is the first investigation to be performed. It showed the ureterocele inside the bladder with a dilated ureter and renal cavities. Renal ultrasound showed pyeloureteral duplication of both systems, the upper pole drains into the ureterocele.

The CT Scan with pyelography has highlighted an aspect of "cobra head" of Anglo-Saxon, generally characteristic of intra-vesical ureteroceles, with or without duplication of the excretory tract. For Brueziere [6], imaging (ultrasound, pyelography, cystography) provides all the necessary information so that cystoscopy no longer appears as a routine examination. The endoscopic exploration has a therapeutic purpose and will be done on full and empty bladder, because the ureterocele can decompress when the bladder is full. In severe and/or complicated forms, renal scan is an interesting contribution to appreciate the function of each renal system, yet in newborns, and in very obstructive forms this examination lacks accuracy. It allows deciding between a conservative surgery and an excisional surgery [2].

The goal of treatment of the ureterocele is to eliminate infection, obstruction and reflux and to maintain urinary continence. The gold standard treatment for intravesical ureterocele is the endoscopic incision [1014]. In our two cases we used open surgery to remove the ureterocele and re-implant the ureters with cohen procedure.

\section{Conclusion}

Intravesical Ureterocele Into Childhoods is a rare congenital anomaly. The treatment depends on the extent of the clinical problems (duplex system, the presence of obstruction and dysplastic hydronephrotic kidney. Endoscopic incision of ureterocele and ureteral reimplantation were efficacies. Other forms of surgical intervention require partial nephroureterectomy of the upper moiety.

\section{REFERENCES}

[1] Campbell M (1951) Ureterocele: a study of 94 instances in 80 infants and children. Surg Gynecol Obstetr 93:705-718.

[2] Peters CA, Mendelsohn C. Ectopic ureter, ureterocele, and ureteral anomalies. In: Wein AJ, 
Intravesical Ureterocele into Childhoods: Report of Two Cases and Review of Literature

Kavoussi LR, Partin AW, Peters CA, eds. CampbellWalsh Urology. 11th ed. Philadelphia, PA: Elsevier; 2016: chap 134.

[3] Malek RS, Kelalis PP, Sticker GB et al. (1972) Observations on ureteral ectopy in children. J Urol 107:308-311.

[4] Sylla C, Diabate I, Fall PA, Diao B, Bah I, Gueye SM, Ndoye A, Ba M, Diagne BA. (2002) Urétérocèle de l'adulte. À propos de cinq cas. Annales d'Urologie $36: 38-41$.

[5] Glassberg KI, Braren V, Duckett JW et al. (1984) Suggested terminology for duplex systems, ectopic ureters and ureteroceles. Report of the Committee on Terminology, Nomenclature and Classification. American Academy of Pediatrics. J Urol 132:1153-1154.

[6] Bruézière J. Urétérocèles. EMC (Elsevier Masson SAS, Paris), Néphrologie, 18-158-C-10. 1990.

[7] Ericsson NO (1954) Ectopic ureteroceles in infants and children. Acta Chirurg Scand [Suppl 197]: 7-21.

[8] Stephens FD (1971) Caeecoureterocele and concepts on the embryology and aetiology of ureteroceles. Aust N Z J Surg 40:257-268.
[9] Coplen D, Duckett JW. The modern approach to ureteroceles. J Urol 1995; 153:69.

[10] Merlini E, Chiesa PL. Obstructive ureterocele-an ongoing challenge. World J Urol 2004 June; 22: 107-14.

[11] P. K. Chhetri 1, S K Malla Ureterocele - A case report Journal of college of Medical SciencesNepal, 2010, Vol.6, No-2, 38-41.

[12] Shokeir AA, Nijman RJM (2002) Ureterocele: an ongoing challenge in infancy and childhood. BJU 90:777-783.

[13] Hagg MJ, Mourachov PV, Snyder HM et al. (2000) The modern endoscopicapproach to ureteroceles. J Urol 163:940-943.

[14] Valla JS, Breaud J, Carfagna L et al. (2003) Treatment of ureterocele on duplex ureter: upper pole nephrectomy by retroperitoneoscopy in children based on a series of 24 cases. Eur Urol 43:426-429.

[15] Xie D, Klopukh B, Nehrenz GM, Gheiler E (2017) Ureterocele: Review of Presentations, Types and Coexisting Diseases. Int Arch Urol Complic 3:024. doi.org/10.23937/2469-5742/1510024

Citation: Kouka Scn, Diallo Y, Ali Mahamat M, et al. Intravesical Ureterocele into Childhoods: Report of Two Cases and Review of Literature. Archives of Urology. 2019; 2(2): 1-4.

Copyright: (C) 2019 Kouka Scn, Diallo Y, Ali Mahamat M, et al. This is an open access article distributed under the Creative Commons Attribution License, which permits unrestricted use, distribution, and reproduction in any medium, provided the original work is properly cited. 